\title{
Awareness of Gynecologists and Mothers about Role of Physical Therapy in the Treatment of Rectus Diastasis Cases
}

\author{
SOHEIR M. EL-KOSERY, Ph.D.*; AHMED G. IBRAHIM, M.Sc.* and EMAN M. MOJAHED, M.D.** \\ The Department of Physical Therapy for Women's Health*, Faculty of Physical Therapy, Cairo University and \\ The Department of Obstetrics \& Gynecology, Faculty of Medicine, El-Fayoum University**
}

\begin{abstract}
Background: Diastasis recti are acondition in which the rectus abdominis muscle separates in the mid line at the linea alba. The diastasis is defined as a gap between the recti abdominis muscles of greater than $2.5 \mathrm{~cm}$. The separation of the linea alba may occur during pregnancy or in the expulsive stage of labor.
\end{abstract}

Aim of Study: Was to investigate awareness of gynecologists and mothers about role of physical therapy in treating rectus diastasis cases.

Subjects and Methods: Group (A) two hundred gynecologists and Group (B) five hundred mothers (from different hospitals in El-Giza Governorate), were participated in this study. They were asked to answer all questions of gynecologist's questionnaire and mother's questionnaire respectively.

Gynecologist's questionnaire to evaluate the awareness of gynecologists about the role of physical therapy in treatment of rectus diastasis. Mother's questionnaire to evaluate the awareness of mothers about the role of physical therapy in treatment of rectus diastasis. The questionnaires were devised based on the literature review to elicit evidence about the awareness about the role of physical therapy in treatment of rectus diastasis cases.

Result: The results of the study revealed that $60.7 \%$ from gynecologists participated in this study reported their appreciation of the importance of physical therapy role and modalities for treating rectus diastasis and $39.3 \%$ had no idea about the role of physical therapy and modalities used in treating rectus diastasis. Also, 27.4\% from mothers heard about physical therapy role and modalities used in treating rectus diastasis and $72.6 \%$ had no idea about the role of physical therapy and modalities used in treating rectus diastasis.

Conclusion: From the previous result, it could be concluded that more awareness is needed for both gynecologists and mothers about role and modalities of physical therapy used in treating rectus diastasis cases.

Key Words: Physical therapy role - Rectus diastasis - Gynecologists - Mothers.

Correspondence to: Dr. Soheir M. El-Kosery, The Department of Physical Therapy for Women's Health, Faculty of Physical Therapy, Cairo University

\section{Introduction}

THE main musculoskeletal problems encounter postnatal women are low back pain, pelvic girdle pain, Diastasis Recti Abdominis (DRA) and poor control of the abdominal muscles [1].

The abdominals consist of several different muscle groups; rectus abdominis, external and internal oblique and transverse abdominis. While the transverse abdominis muscles wraps around the front of the trunk horizontally from one side to other side, the rectus abdominis and the oblique muscles are vertically separated along the midline of the abdomen by a fibrous connective tissue called linea alba [2].

Diastasis recti are acondition in which the rectus abdominis muscle separates in the mid line at the linea alba. The diastasis is defined as a gap between the recti abdominis muscles of greater than $2.5 \mathrm{~cm}$. The separation of the linea alba may occur during pregnancy or in the expulsive stage of labor [3]

Diastasis recti abdominis occurs in $60 \%$ of post-partum with the rectus abdominis elongating as the fetus grows. Many factors can contribute to the development of adivearcation ( $>2 \mathrm{~cm}$ wide) including successive pregnancies, carrying a large baby, multiple birth pregnancy, excess uterine fluid, obesity and over use of the abdominal musculature against resistance during pregnancy [4].

During pregnancy, hormonal changes caused by relaxin, progesterone and estrogen combined with uterine growth may cause stretching of the abdominal muscles, affecting mainly the rectus abdominis muscles. Also during pregnancy, it is common to have anterior pelvic tilt with or without lumbar hyperlordosis. These postural changes can affect the insertion angle of pelvic and abdominal 
muscles, influencing postural biomechanics. The biomechanical changes and stretching of these stretch, there is a loss in the force vector of these muscles, and there may be muscles facilitate the appearance of diastasis of the rectus abdominis muscles (DRA). The DRA evaluation and the value to be considered are especially important among physical therapists because these professionals are concerned with the functionality and physical integrity of individuals. A DRA of more than $2.5 \mathrm{~cm}$ can be considered harmful as it may interfere with the abdominal muscles ability to stabilize the trunk and functions such as posture, bowel movements, parturition, trunk movements as well as visceral support and lumbar stabilization [5].

Diastasis recti are relatively uncommon at first trimester, progresses reaching peak at third trimester. It is less common in woman with good abdominal tone prior to pregnancy [6].

The symptoms of diastasis recti are women with diastasis recti usually.

Perceive no pain at rest, whereas discomfort, pain, corset instability and bulging of the abdominal wall are symptoms appearing during physical activities. Women may have a small percentage of pain when the diastasis recti is quite large, this may be in the (lower) back or within the abdominals It is commonly seen in multiparous women because the muscles have been stretched many times. In the later part of pregnancy, the top of the pregnant uterus is often seen bulging out of the abdominal wall [7].

Computed Tomography (CT) is considered the gold standard to evaluate the abdominal wall, but this exposes the patient to radiation and has high cost. The Ultrasonography (US) has relative cost, and is a non invasive technique, but requires training and technical image quality which may be affected by the interposition of fat and fibrosis. Thus, physiotherapists measure the (DRA) postnatal with the fingertips which are a more practical way and estimate the distance and the width of the rectus abdominis muscles of the fingers. However, such a measure can be questioned due to individual variations ranging between examiners. Therefore, it has been suggested the use of a caliper which is considered as an simple instrument, inexpensive and more objective [8].

Isokinetic assessment allows clinician to objectively assess muscular performance in a way that is both safe and reliable. Isokinetic testing affords the clinician objective criteria and provides reproducible data to assess and monitor a patient's status.
Isokinetic testing has been demonstrated to be reliable and valid [9].

\section{Subjects, Material and Methods}

Subjects:

- Group (A): Consisted of two hundreds gynecologists who were selected randomly from different hospitals at Giza governorate. They were asked to answer all the questions of gynecologists questionnaire (Appendix II).

- Group (B): Consisted of five hundreds mothers who were selected randomly from different hospitals at Giza governorate. They were asked to answer all the questions of mother's questionnaire (Appendix III).

These subjects were chosen under the following criteria:

1- Gynecologists who had a master degree.

2 - The age of the mothers were ranged from 25 to 35 years old.

3- Mothers were multipara.

Duration of the study: Was 6 months from April to September 2019, at different hospitals at Giza governorate.

\section{Methods:}

Evaluation procedures:

- All subjects agreed to participate in the study by completing an informed consent.

- Gynecologist's questionnaire to evaluate the awareness of obstetricians about the role of physical therapy in treatment of rectus diastasis.

- Mother's questionnaire to evaluate the awareness of mothers about the role of physical therapy in treatment of rectus diastasis.

The questionnaires were devised based on the literature review to elicit evidence about the awareness about the role of physical therapy in treatment of rectus diastasis cases.

\section{Material:}

Evaluation material:

1- Isokinetic dynamometry.

2- Electronic digital caliper.

3- Ultrasonography.

4- Finger test.

5- Sociodemographic and evaluation. 


\section{Questionnaires:}

Were used to assess the awareness of gynecologists and mothers about the role of physical therapy in treatment of rectus diastasis cases.

\section{Statistical analysis:}

Collected data was fed into a computer system for statistical analysis using descriptive statistics, percentages and means.

\section{Results}

200 gynecologists (group A) and 500 mothers (group B) were selected randomly from different hospitals in Giza governorate who answered all the questions of gynecologist's questionnaire and mother's questionnaire respectively.

Total response of gynecologist's questionnaire (group A) to survey questions:

Table (1): Represent the number and percentage of different responses for each question in the questionnaire answered by the participated gynecologists in (group A).

\begin{tabular}{|c|c|}
\hline $\begin{array}{l}\text { - For } \\
\text { question } \\
1\end{array}$ & $\begin{array}{l}\text { - There were } 200 \text { gynecologists }(100 \%) \text { answered } \\
\text { by "No", and } 0 \text { gynecologists }(0 \%) \text { answered } \\
\text { by "Yes". }\end{array}$ \\
\hline $\begin{array}{l}\text { - For } \\
\text { question } \\
2\end{array}$ & $\begin{array}{l}\text { - There were } 12 \text { gynecologists (6\%) answered } \\
\text { by "No", and } 188 \text { gynecologists }(94 \%) \\
\text { answered by "Yes". }\end{array}$ \\
\hline $\begin{array}{l}\text { - For } \\
\text { question } \\
3\end{array}$ & $\begin{array}{l}\text { - There were } 200 \text { gynecologists }(100 \%) \text { answered } \\
\text { by "No", and } 0 \text { gynecologists }(0 \%) \text { answered } \\
\text { by "Yes". }\end{array}$ \\
\hline $\begin{array}{l}\text { - For } \\
\text { question } \\
4\end{array}$ & $\begin{array}{l}\text { - There were } 12 \text { gynecologists (6\%) answered } \\
\text { by "No", and } 188 \text { gynecologists }(94 \%) \\
\text { answered by "Yes". }\end{array}$ \\
\hline $\begin{array}{l}\text { - For } \\
\text { question } \\
5\end{array}$ & $\begin{array}{l}\text { - There were } 25 \text { gynecologists }(12.5 \%) \text { answered } \\
\text { by "No", and } 175 \text { gynecologists }(87.5 \%) \\
\text { answered by "Yes". }\end{array}$ \\
\hline $\begin{array}{l}\text { - For } \\
\text { question } \\
6\end{array}$ & $\begin{array}{l}\text { - There were } 12 \text { gynecologists }(6 \%) \text { answered } \\
\text { by "No", and } 188 \text { gynecologists }(94 \%) \\
\text { answered by "Yes". }\end{array}$ \\
\hline $\begin{array}{l}\text { - For } \\
\text { question } \\
7\end{array}$ & $\begin{array}{l}\text { - There were } 113 \text { gynecologists }(56.5 \%) \\
\text { answered by "No", and } 87 \text { gynecologists } \\
(43.5 \%) \text { answered by "Yes". }\end{array}$ \\
\hline $\begin{array}{l}\text { - For } \\
\text { question } \\
8\end{array}$ & $\begin{array}{l}\text { - There were } 138 \text { gynecologists ( } 69 \%) \text { answered } \\
\text { by "No", and } 62 \text { gynecologists (31\%) answered } \\
\text { by "Yes". }\end{array}$ \\
\hline $\begin{array}{l}\text { - For } \\
\text { question } \\
9\end{array}$ & $\begin{array}{l}\text { - There were } 37 \text { gynecologists }(18.5 \%) \text { answered } \\
\text { by "No", and } 163 \text { gynecologists }(81.5 \%) \\
\text { answered by "Yes". }\end{array}$ \\
\hline $\begin{array}{l}\text { - For } \\
\text { question } \\
10\end{array}$ & $\begin{array}{l}\text { - There were } 49 \text { gynecologists }(24.5 \%) \text { answered } \\
\text { by "No", and } 151 \text { gynecologists }(75.5 \%) \\
\text { answered by "Yes". }\end{array}$ \\
\hline $\begin{array}{l}\text { - For } \\
\text { question } \\
11\end{array}$ & $\begin{array}{l}\text { - There were } 75 \text { gynecologists }(37.5 \%) \text { answered } \\
\text { by "No", and } 125 \text { gynecologists }(62.5 \%) \\
\text { answered by "Yes". }\end{array}$ \\
\hline $\begin{array}{l}- \text { For } \\
\text { question } \\
12\end{array}$ & $\begin{array}{l}\text { - There were } 71 \text { gynecologists }(35.5 \%) \text { answered } \\
\text { by "No", and } 129 \text { gynecologists }(64.5 \%) \\
\text { answered by "Yes". }\end{array}$ \\
\hline
\end{tabular}

Table (2): Number and percentage of responses to survey questions of gynecologists (group A).

\begin{tabular}{|c|c|c|}
\hline \multirow[b]{2}{*}{ Questions } & \multicolumn{2}{|c|}{ Response } \\
\hline & $\begin{array}{l}\text { Yes \% } \\
\mathrm{N}(\%)\end{array}$ & $\begin{array}{l}\text { No } \% \\
\mathrm{~N}(\%)\end{array}$ \\
\hline Q1 & $0 \quad(0 \%)$ & $200(100 \%)$ \\
\hline $\mathrm{Q}^{2}$ & $188(94 \%)$ & $12 \quad(6 \%)$ \\
\hline Q3 & $(0 \%)$ & $200(100 \%)$ \\
\hline Q4 & $188(94 \%)$ & $12(6 \%)$ \\
\hline Q5 & $175(87.5 \%)$ & $25 \quad(12.5 \%)$ \\
\hline Q6 & $188(94 \%)$ & $12 \quad(6 \%)$ \\
\hline$Q^{7}$ & $87 \quad(43.5 \%)$ & $113(56.5 \%)$ \\
\hline $\mathrm{Q}^{8}$ & $62(31 \%)$ & $138(69 \%)$ \\
\hline Q9 & $163(81.5 \%)$ & $37(18.5 \%)$ \\
\hline Q10 & $151(75.5 \%)$ & $49(24.5 \%)$ \\
\hline Q11 & $125(62.5 \%)$ & $75(37.5 \%)$ \\
\hline Q12 & $129(64.5 \%)$ & $71(35.5 \%)$ \\
\hline
\end{tabular}

Total response of mother's questionnaire (group B) to survey questions:

Table (3): Represents the number and percentage of different responses for each question in the questionnaire answered by the participated mothers in (group B).

- For question 1; there were 220 women (44\%) answered by "No", and 280 women (56\%) answered by "Yes".

- For question 2; there were 440 women (88\%) answered by "No", and 60 women (12\%) answered by "Yes".

- For question 3 ; there were 380 women $(76 \%)$ answered by "No", and 120 women (24\%) answered by "Yes".

- For question 4 ; there were 440 women $(88 \%)$ answered by "No", and 60 women (12\%) answered by "Yes".

- For question 5; there were 360 women (72\%) answered by "No", and 140 women (28\%) answered by "Yes".

- For question 6; there were 440 women (88\%) answered by "No", and 60 women (12\%) answered by "Yes".

- For question 7; there were 400 women $(80 \%)$ answered by "No", and 100 women (20\%) answered by "Yes".

- For question 8 ; there were 500 women $(100 \%)$ answered by "No", and 0 women ( $0 \%)$ answered by "Yes".

- For question 9; there were 360 women (72\%) answered by "No", and 140 women (28\%) answered by "Yes".

- For question 10; there were 480 women (96\%) answered by "NO"and 20 women (4\%) answered by "Yes".

- For question 11 ; there were 280 women (56\%) answered by "No", and 220 women (44\%) answered by "Yes".

- For question 12; there were 320 women (64\%) answered by "No, and 180 women (36\%) answered by "Yes".

- For question 13; there were 190 women (38\%) answered by "No", and 310 women (62\%) answered by "Yes".

- For question 14; there were 270 women (54\%) answered by "No", and 230 women (46\%) answered by "Yes". 


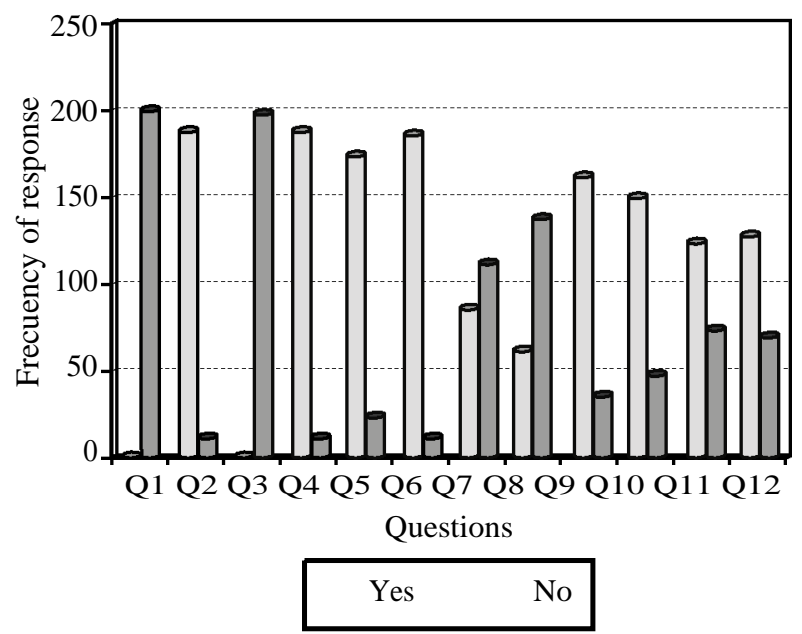

Fig. (1): The number of responses to the survey questions of gynecologists (group A).

Table (4): Number and percentage of responses to survey questions of mothers (group B).

\begin{tabular}{|c|c|c|}
\hline \multirow[b]{2}{*}{ Questions } & \multicolumn{2}{|c|}{ Response } \\
\hline & $\begin{array}{l}\text { Yes \% } \\
\text { N }(\%)\end{array}$ & $\begin{array}{l}\text { No \% } \\
\text { N }(\%)\end{array}$ \\
\hline Q1 & $280(56 \%)$ & $220(44 \%)$ \\
\hline Q2 & $60 \quad(12 \%)$ & $440(88 \%)$ \\
\hline Q3 & $120(24 \%)$ & $380(76 \%)$ \\
\hline Q4 & $60 \quad(12 \%)$ & $440(88 \%)$ \\
\hline Q5 & $140(28 \%)$ & $360(72 \%)$ \\
\hline Q6 & $60 \quad(12 \%)$ & $440(88 \%)$ \\
\hline Q7 & $100(20 \%)$ & $400(80 \%)$ \\
\hline Q8 & $0 \quad(0 \%)$ & $500(100 \%)$ \\
\hline Q9 & $140(28 \%)$ & $360(72 \%)$ \\
\hline Q10 & $20 \quad(4 \%)$ & $480(96 \%)$ \\
\hline Q11 & $220(44 \%)$ & $280(56 \%)$ \\
\hline Q12 & $180(36 \%)$ & $320(64 \%)$ \\
\hline Q13 & $310(62 \%)$ & $190(38 \%)$ \\
\hline Q14 & $230(46 \%)$ & $270(54 \%)$ \\
\hline
\end{tabular}

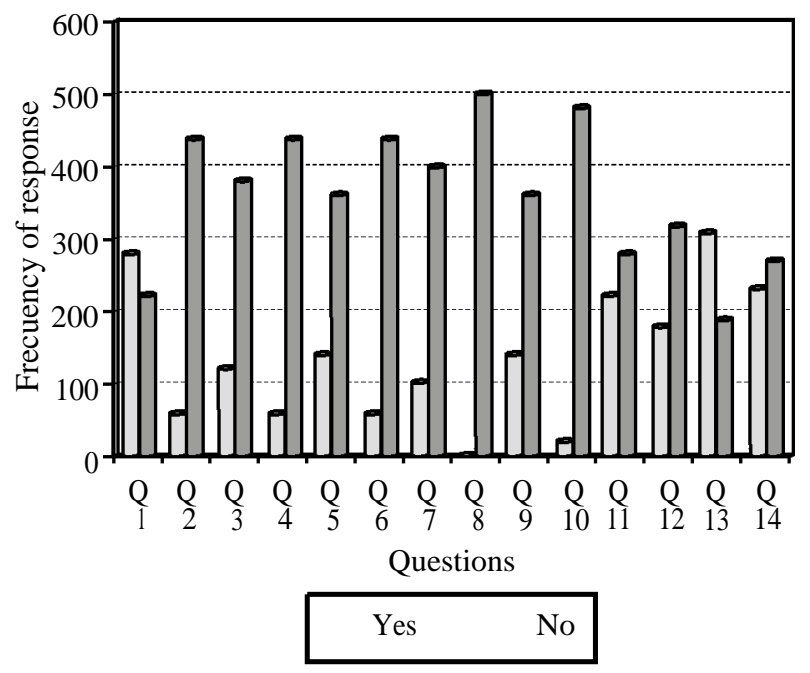

Fig. (2): The number of responses to the survey questions for all mothers (group B).

\section{Discussion}

This study was designed to assess awareness of gynaecologists and mothers about role of physical therapy in treatment of rectus diastasis cases.

The results of this study were classified and discussed under two main parts:

1- The results of the gynecologist's questionnaire which composed of 12 questions that had given to 200 gynecologists who selected from different hospitals.

$0 \%$ from gynecologists believed that preventing rectus abdominis diastasis is not limited to medical treatment only, 94\% from gynecologists believed that physical therapy methods are important for preventing rectus abdominis diastasis, $0 \%$ from gynecologists believed that treatment of rectus abdominis diastasis is not limited to medical treatment only, 94\% from gynecologists believed that physical therapy methods are important in treatment of rectus abdominis diastasis, $87.5 \%$ from gynecologists believed that physical therapy methods important in pre and post labour, $94 \%$ from gynecologists believed that controlling of rectus abdominis diastasis arole of teamwork including gynecologist \& physiotherapist, $43.5 \%$ from gynecologists have an idea about physical therapy modalities used to treat rectus abdominis diastasis, $31 \%$ from gynecologists refer cases of rectus abdominis diastasis to physical therapy before, $81.5 \%$ from gynecologists believed that physical therapy methods safe in treatment of rectus abdominis diastasis, $75.5 \%$ from gynecologists believed that core muscle training important to treat rectus abdominis diastasis, $62.5 \%$ from gynecologists believed that tupler exercise important to treat rectus abdominis diastasis and $64.5 \%$ from gynecologists believed that faradic therapy important to treat rectus abdominis diastasis.

$100 \%$ from gynecologists believed that preventing rectus abdominis diastasis is limited to medical treatment only, $6 \%$ from gynecologists believed that physical therapy methods are not important for preventing rectus abdominis diastasis, $100 \%$ from gynecologists believed that treatment of rectus abdominis diastasis is limited to medical treatment only, $6 \%$ from gynecologists believed that physical therapy methods are not important in treatment of rectus abdominis diastasis, $12.5 \%$ from gynecologists believed that physical therapy methods are not important in pre and post labour, $6 \%$ from gynecologists don't believed that controlling of rectus abdominis diastasis a role of teamwork including gynecologist \& physiotherapist, $56.5 \%$ 
from gynecologists had no idea about physical therapy modalities used to treat rectus abdominis diastasis, $69 \%$ from gynecologists refer cases of rectus abdominis diastasis to physical therapy before, $18.5 \%$ from gynecologists believed that physical therapy methods are not safe in treatment of rectus abdominis diastasis and $24.5 \%$ from gynecologists had no idea about core muscle training important to treat rectus abdominis diastasis, 37.5 from gynecologists had no idea about tubler exercise is important to treat rectus abdominis diastasis, $35.5 \%$ from gynecologists had no idea about faradic therapy is important to treat rectus abdominis diastasis.

These results reflected lack of awareness of gynecologists about role of physical therapy in treatment of rectus diastasis cases.

2- The results of mother's questionnaire which had composed of 14 questions that had given to 500 mothers aged from 25 to 35 years old. Concerning questions number (1) and (2): Did you hear about physical therapy modalities used in treating rectus abdominis diastasis? And did you use any physical therapy modalities used in treating rectus abdominis diastasis? 56\% from mothers heard about physical therapy modalities used for treating rectus abdominis diastasis and $44 \%$ from them did not hear about this, $12 \%$ from who heard about physical therapy modalities used these modalities and $88 \%$ didn't use these modalities.

Concerning questions number (3) and (4) did you hear about exercise for treating rectus abdominis diastasis? And did you use exercise for treating rectus abdominis diastasis? 24\% from mothers heard about exercise for treating rectus abdominis diastasis and $76 \%$ from mothers did not hear about exercise for treating rectus abdominis diastasis, $12 \%$ from mothers used exercise for treating rectus abdominis diastasis, and $88 \%$ did not use exercise for treating rectus abdominis diastasis.

Concerning questions number (5) and (6): Did you hear about electrical stimulation for treating rectus abdominis diastasis? And did you use electrical stimulation for treating rectus abdominis diastasis? 28\% from mothers heard about electrical stimulation for treating rectus abdominis diastasis and $72 \%$ from mothers did not hear about this, $12 \%$ from mothers used electrical stimulation for treating rectus abdominis diastasis, and $88 \%$ did not use electrical stimulation for treating rectus abdominis diastasis.

Concerning questions number (7) and (8): Did you hear about importance of exercise before pregnancy in preventing rectus abdominis diastasis? And did you use exercise before pregnancy to prevent rectus abdominis diastasis?

$20 \%$ from mothers heard about importance of exercise before pregnancy in preventing rectus abdominis diastasis and $80 \%$ from mothers did not hear about importance of exercise before pregnancy in preventing rectus abdominis diastasis, $0 \%$ from mothers used exercise before pregnancy for preventing rectus abdominis diastasis, and $100 \%$ did not use exercise before pregnancy for preventing rectus abdominis diastasis.

Concerning questions number (9) and (10): Did you hear about importance of exercises during pregnancy in preventing rectus abdominis diastasis? And did you use exercises during pregnancy in preventing rectus abdominis diastasis? 28\% from mothers heard about importance of exercises during pregnancy in preventing rectus abdominis diastasis and $72 \%$ from mothers did not hear about importance of exercises during pregnancy in preventing rectus abdominis diastasis, $4 \%$ from mothers used exercises during pregnancy for preventing rectus abdominis diastasis, and $96 \%$ did not use exercises during pregnancy for preventing rectus abdominis diastasis.

Concerning questions number (11) and (12): Did you hear about importance of exercise after labour in preventing rectus abdominis diastasis? and Did you use exercise after labour in preventing rectus abdominis diastasis? $44 \%$ from mothers heard about importance of exercise after labour in preventing rectus abdominis diastasis and $56 \%$ did not hear about this. $36 \%$ from mothers used exercise after labour for preventing rectus abdominis diastasis, and $64 \%$ did not use exercise after labour for preventing rectus abdominis diastasis.

Concerning questions number (13) and (14): Did you use abdominal belt to treat rectus abdominis diastasis after labour? And are physical therapy methods safe in treatment of rectus abdominis diastasis? 62\% from mothers use abdominal belt to treat rectus abdominis diastasis after labour and $38 \%$ did not use abdominal belt after labour.

$46 \%$ from mothers believed that physical therapy methods are safe in treatment of rectus abdominis diastasis, and 54\% did not believed that physical therapy methods are safe in treatment of rectus abdominis diastasis.

These results reflected the lack of awareness of mothers about the role of physical therapy in treatment of rectus diastasis cases. 
So finally, physiotherapists work as part of a multi-disciplinary team and are generally dependent on consultants and the primary health care team for patient referral.

\section{Conclusion:}

This study was a trial to investigate the awareness of Egyptian gynecologists and mothers about physical therapy role and modalities used in treating rectus diastasis.

For this purpose, 200 gynecologists (group A) and 500 mothers (group B) were selected randomly from different hospitals in El-Giza govemorate who answered all the questions of gynecologist's questionnaire and mother's questionnaire respectively.

The results of this study were classified and discussed under two main parts:

1- The results of gynecologists' questionnaire which had been composed of 12 questions that given to 200 gynecologists.

2- The results of mother's questionnaire which had been composed of 14 questions that given to 500 mothers. The results of this study showed that $60.7 \%$ from gynecologists who participated in this study reported their appreciation to the importance of physical therapy role and modalities used for treating rectus diastasis and 39.3\% of them had no idea about physical therapy role and modalities used for treating rectus diastasis cases. Although, $27.4 \%$ from mothers heard about physical therapy role and modalities used for treating rectus diastasis and $72.6 \%$ from them did not hear about this.

So, we could conclude that more awareness is needed for both gynecologists and mothers about physical therapy role used for treating rectus diastasis.

\section{References}

1- COLDRON Y., STROTES M., NEWHAM D. and COOK K.: "Postpartum characteristics of rectus abdominis on ultrasound imaging". Manual therapy J., (13): 112-21, 2008.

2- MISHA A., MARIA L.,UMAR M. and KANWAL R.: Prevalence ofdiastasis recti among presenting at Holy Family Hospital Rawalpindi. Int. J. Rehabil. Sci., 3 (1): 26-31, 2013.

3- OKEEL F., EL-BADRY S. and YOUSEF A.: "Essentials of obstetrics and gynocology for physical therapist". Textbook, $10^{\text {th }}$ Ed, Tiba press, 70-2, 2010.

4- JESSICA K., MELISSA A., LAUREN E., LAURA H., CHANTAL D. and DEBORAH L.: Diastasis recti abdominis: A survey ofwomen's health specialists for current physical therapy clinical practice for post partum women, Journal of Women's Health Physical Therapy, 36 (3): 131-42, 2012

5- RETT M., BRAGA M., BERNARDES N. and ANDRADE S.: Prevalencae of diastasis of the rectus abdominis muscles immediately postpartum: Comparison between primiparae and multiparae, Brazilian Journal of Physical Therapy, 13 (4): 275-80, 2009.

6- KLEIN M.: The 2 nd Asia Pacific Congress on controversies in Obstetrics Gynecology and Infertilty, (COG 10) Shanghai, China, November 8-11, 2007.

7- SANJIVANI R. and DEEPALI H.: Effects of Abdominal Exercises on reduction of Diastasis Recti in Postnatal Women. International Journal of Health Sciences \& Research, 6 (6): 182-91, 2016.

8- RETT M., ARAUJO F., ROCHA I. and SILVA R.: Diastasis of rectusabdominis muscles in the immediate postpartum period ofprimiparas and multiparas after vaginal ophthalmosis. Fisioter. Pesq., 19 (3): 236-41, 2012.

9- GEORGE J., DAVIES and TODD S.: The application of isokinetics in testing and rehabilitation of the shoulder complex, Journal of athletic training, v. 35, n. p. 338-50, 2000. 


\section{ملى معرفة آطباء النساء والآمهات بلدور العلاج الطبيعى

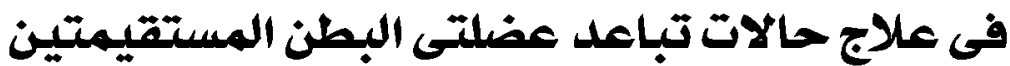

الهدف: آجريت هذه الدراسة لتقييم مستوى الإدراك بلود العلاج الطبيعى في علاج حالات تباعد عضلتى البطن المستقيمتين لدى آطباء النساءوالآمهات.

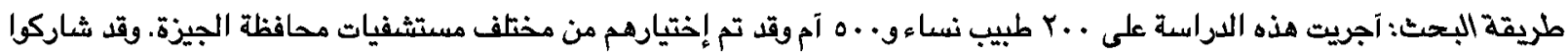
في هذه الدراسة عن طريق الإجابة على إستيان هذهان صمم لذلك.

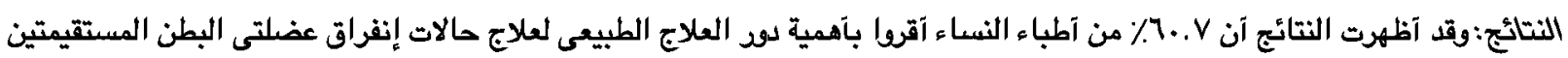

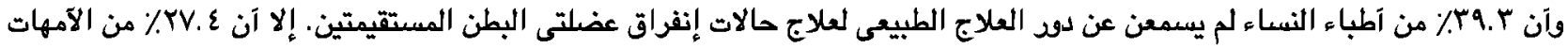

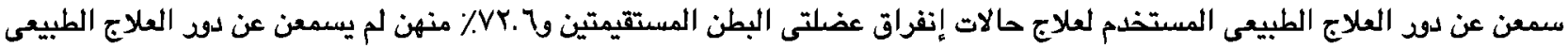

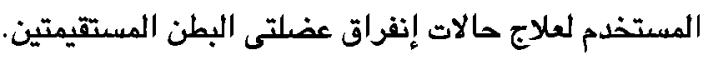

الخلاصة: لذلك يمكن آن نستخلص آن هناك حاجة إلى المزيد من التوعية بلود العلاج الطبيعى فى علاج حالات إنفراق عضلتى البطن

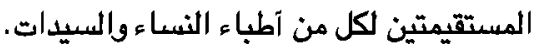

